Como citar este artículo en APA: Muenala Valverde, G. (2019). La praxis de la encarnación, propuesta de Simone Weil para contravenir la dinámica de la fuerza y la gravedad que rigen el orden social. Cuestiones Teológicas, 46 (105), 165-190. doi: http://dx.doi.org/10.18566/cueteo.v46n105.a07

Fecha de recepción: 02.04.2019 Fecha de aceptación: 29.04.2019

\title{
LA PRAXIS DE LA ENCARNACIÓN EN EL PENSAMIENTO DE SIMONE WEIL ${ }^{1}$
}

\author{
Praxis of incarnation in simone weil's thought \\ A praxis da encarnação no pensamento de simone weil \\ Galo Patricio Muenala Valverde ${ }^{2}$
}

1 Este trabajo es derivado de la Tesis para obtener el título de maestría en Filosofía y Pensamiento Social, Convocatoria 2016-2018, en la Facultad Latinoamericana de Ciencias Sociales, FLACSO, Ecuador.

2 Licenciado en Teología Bíblica por la Universidad de Navarra, España. Maestrando en Filosofía y Pensamiento Social, Flacso, Ecuador. Actualmente se desempeña como docente en el Instituto Franciscano de Teología y Filosofía "Cardenal Echeverría", Quito-Ecuador.

Correo electrónico: galisimus@yahoo.es 


\section{Resumen}

Simone Weil (1909-1943) fue una filósofa y mística francesa de procedencia judía. Entre los conceptos más importantes de su pensamiento destaca el de la encarnación, pero principalmente el de praxis de la encarnación, como una alternativa que tiene el ser humano para contravenir el mecanismo de la fuerza, de la gravedad y del poder de la colectividad, causantes de opresión social. Para abordar el presente trabajo se recurre principalmente a la lectura y análisis atento de sus principales escritos, como: Reflexiones sobre las causas de la libertad y de la opresión social, A la espera de Dios, La gravedad y la gracia, El conocimiento sobrenatural, etc. Al fin del trabajo se reconoce la importancia de la praxis de la encarnación, la cual puede ser efectiva para cambiar, aunque sea en un grado infinitesimal, la vida personal y social, de tal manera que los bienes trascendentes del bien, la verdad, la belleza y la justicia se encarnen en el orden social vigente.

Palabras clave: Simone Weil, opresión social, gracia sobrenatural, praxis de la Encarnación.

\section{Abstract}

Simone Weil (1909-1943) was a French philosopher and mystic of Jewish origin. Among her most relevant concepts, we can highlight that of incarnation, but most significant is that of praxis of incarnation, which is an option of human beings to contravene the mechanism of power, gravity and the power of the social element; which are the causes of social oppression. Thus, the article proposes a critical reading and analysis of some of her writings, such as "Reflections concerning the Causes of Liberty and Social Oppression", Waiting for God, Gravity and Grace, Supernatural Knowledge, among others. It concludes by acknowledging the importance of praxis of incarnation, which might be useful for changing personal and social life -even if it is in a slight degree- in such a way that the transcendental goods of goodness, truth, beauty and justice become incarnated within the current social order.

Key Words: Simone Weil, Social Oppression, Supernatural Grace, Praxis of Incarnation. 


\section{Resumo}

Simone Weil (1909-1943) foi uma filosofa e mística francesa de origem judia. Entre os conceitos mais importantes de seu pensamento se distingue o conceito da encarnação, mas exatamente o conceito praxis da encarnação, como uma alternativa que tem o ser humano para questionar o mecanismo da força, enquanto causas da opressão social, a magnitude e o poder da coletividade. Para isso, esse artigo apresenta, basicamente, uma leitura e uma análise cuidadosas de seus principais textos, tais como: Reflexóes sobre as causas da liberdade e da opressão social, Espera de Deus, A gravidade e a graça, O conhecimento sobrenatural, etc. Finalmente, esse artigo reconhece a importância da práxis da encarnação, a qual pode ser efetiva para mudar -embora seja num grau infinitésimo- a vida pessoal e social, desta maneira, os bens transcendentais do bem, da verdade, da beleza e da justiça se encarnam na ordem social atual.

Palabras-chave: Simone Weil, opressão social, graça sobrenatural, praxis da encarnação.

\section{Introducción}

La idea de encarnación (incarnation) y principalmente la praxis de la encarnación, es un tema fundamental en el pensamiento filosófico, teológico, antropológico y social de Simone Weil. El concepto de encarnación está en el trasfondo de una constelación de nociones usadas por la autora, tales como: abajamiento, anonadamiento, renuncia de sí mismo, vacío, decreación, etc. La noción de encarnación parece informar además, la manera en la que Simone Weil trata los principales problemas filosóficos sobre el bien, la verdad, la belleza, la justicia, la atención, etc. La praxis de la encarnación, se entiende como un movimiento de descenso a la realidad, pero que es al mismo tiempo renuncia similar a aquella que define la experiencia estética, es decir, un movimiento de retirada.

Según la autora, en el orden social, el ser humano se encuentra sometido al poder de la colectividad y a la fuerza que rige ese orden social, lo cual aplasta los espíritus, fabrica la inconciencia, es causa de opresión, hace de los 
seres humanos seres frágiles, vulnerables, y los expone siempre a la desgracia y a múltiples necesidades. Además, el ser humano se encuentra sometido a una fuerza interior que Simone Weil llama gravedad, que lo mantiene inserto en el medio material; sometido a la necesidad implacable del alma y del cuerpo; y a la aspiración del bien, el cual, es también carencia esencial del ser humano.

Tal parece ser la situación de la historia humana: "[...] la historia de la esclavitud, que hace de los hombres, tanto de los opresores como de los oprimidos [...] un objeto de materia inerte" (Weil, 2015, p. 52). Lo peor de todo, parece ser que el ser humano está cómodo en esa situación y no quiere salir de ella: "Parece que el hombre haya nacido esclavo y que la servidumbre sea su condición propia" (Weil, 2015, p. 64). Del mismo modo, parece que el ejercicio de la fuerza sea lo "natural" (Weil, 2007b, p. 53). Y, aparentemente, "[...] siempre hay que esperar que las cosas sucedan conforme a la gravedad" (Weil, 2007b, p. 53). Ante esta situación, ¿existe alguna posibilidad de escapar de la dinámica de la fuerza, de la gravedad y del poder de la colectividad?

Una alternativa que Simone Weil propone para escapar a esa situación es conocer "las causas de la opresión" (Weil, 2007a, p. 106), y cuestionar todo, "so pena de hundirse en el desconcierto o en la inconsciencia" (Weil, 2015, p. 23). Pero, principalmente, propone la praxis de la encarnación, según la cual, el ser humano puede realizar "el acto de encarnarse" (Weil, 2001, p. 410). Se trata de un acto sobrenatural porque puede contravenir lo que parece natural: fundirse en lo colectivo, ejercer la fuerza y seguir la ley de la gravedad que siempre tiende a la bajeza. Pero, ¿̨cómo articular la existencia de los seres humanos en el medio social con lo que Simone Weil llama lo sobrenatural?

Desde esta perspectiva, el objetivo de este trabajo es presentar un breve panorama del pensamiento de Simone Weil sobre el mecanismo de la opresión social; pero principalmente, se trata de comprender a causa de qué, teóricamente, podría desaparecer, y en virtud de qué, se podría escapar a la dinámica de la fuerza, de la gravedad y del poder de la colectividad. En consecuencia, también se pretende mostrar la forma en que Simone Weil articula la existencia de los seres humanos en el medio social con lo sobrenatural. 
La bibliografía sobre Simone Weil acerca de cuestiones políticas y sociales es muy amplia y valiosa; no así sobre cuestiones religiosas, ni tampoco sobre la temática específica aquí abordada. Por ello, para realizar el presente trabajo se recurre a una lectura y a un análisis atento de sus principales escritos. Este acercamiento a su obra resulta un desafío, puesto que la mayoría de sus escritos son notas escritas para sí misma; algunos son trabajos que había redactado para sus cursos de la Universidad; otros tienen la forma de largos ensayos, y muy pocos han sido escritos bajo un formato similar al de un libro.

El presente trabajo se organiza de la siguiente manera: en primer lugar, trata de describir brevemente la opresión en la que se encuentra el ser humano (I, II); seguidamente, se analiza la propuesta weiliana para escapar a esa opresión (III, IV y V).

\section{Las relaciones humanas sometidas al poder de la fuerza y al gran animal social}

La vocación de Simone Weil fue estar siempre "entre los hombres y vivir en diferentes medios humanos" fundiéndose con ellos "adoptando su mismo color [...], desapareciendo en ellos, a fin de que se muestren tal como son sin que tengan que disfrazarse" (Weil 1996a, p. 28). Así, llevada por la imperiosa necesidad de conocer desde dentro la opresión de los obreros, entre 1934 y 1935 trabajó en distintas fábricas (Alsthom, Renault, etc.). En 1936 participó brevemente en la guerra civil española. A mediados de 1940, ante la inminente invasión alemana, Simone Weil junto a su familia abandonó París hasta llegar Marsella. Allí conoció en 1941 al sacerdote dominico Joseph-Marie Perrin a quien le compartió el deseo de participar de la misma suerte de los trabajadores del campo, y vivir como ellos. El padre Perrin le puso en contacto con Gustave Thibon, un escritor católico quien le permitió trabajar como obrera en su granja, sometiéndose al trabajo y a las mismas necesidades que sufre una peona en la granja (Pétrement, 1997, p. 593).

Desde temprana edad, Simone Weil sintió una simpatía especial por aquellos grupos que se identificaban con las "capas" más maltratadas y 
"despreciadas de la jerarquía social" (Weil, 2007a, p. 522). Por ejemplo, durante el periodo de trabajo en la fábrica Alsthom, le decía en una carta a una antigua alumna: "[...] me siento la hermana de la chica que hace la calle, de todos los seres despreciados, humillados, tratados como deshechos" (Weil, 2014, p. 44). Pero su vida estuvo principalmente marcada por su preocupación de la condición obrera: quería entender desde dentro los problemas de los trabajadores, quería formular y hacer visibles "las causas de la opresión" social y política de su época, causas que pueden conservar su vigencia hasta la actualidad (Weil, 2007a, p. 106).

En 1934, en su obra Reflexiones sobre las causas de la libertady la opresión social, puso en evidencia que, en el orden social, los seres humanos -tanto los poderosos como los débiles- se encuentran sumidos en "el juego mismo de la vida colectiva, un juego ciego [...] algo absolutamente abstracto, absolutamente misterioso, inaccesible a los sentidos y al pensamiento" (Weil, 2015, p. 76). Todos los ámbitos de la vida individual del ser humano, su pensamiento y su acción, la ciencia y la técnica, todo está sometido a lo colectivo, que también es llamado animal social y máquina social. La riqueza, el dinero, el poder, el prestigio, la fama, las distinciones y los honores de toda clase, etc., pertenecen al ámbito de lo social. De este modo, lo social "hace las veces de pantalla" entre el hombre y las cosas elementales para vivir; entre el hombre y la naturaleza (Weil, 2001, p. 32). Así por ejemplo: “[...] la mayoría de los hombres solo puede conseguir la mayor parte de las cosas que consume por medio de la sociedad y a cambio de dinero" (Weil, 2015, p. 90). De ahí que la máquina social causa opresión, destroza los corazones, aplasta los espíritus, fabrica "la inconciencia, la necedad, la corrupción, la debilidad y, sobre todo, el vértigo" (Weil, 2015, p. 87). El abandono en la colectividad hace a los hombres incapaces de pensar, y allí "donde las opiniones irracionales sustituyen a las ideas, la fuerza lo puede todo"; es decir, la ausencia de pensamiento "permite la imposición por la fuerza de doctrinas oficiales enteramente desprovistas de significación” (Weil, 2015, p. 96).

Su formación intelectual, su experiencia sindical y política le dieron una imagen de la dinámica que regía la época en la que le tocó vivir: todo estaba regido por la fuerza (force). En el orden social y político "un sombrío juego de fuerzas ciegas [...] se unen o se enfrentan, [...] progresan o decaen, sin dejar jamás de triturar a los desdichados humanos" (Weil, 2015, p. 60). El trabajo en la fábrica le permitió experimentar en carne propia el poder de 
la fuerza y sus efectos; y en la participación de la guerra de Espańa (1936) encontró la más alta expresión del poder de la fuerza: “[...] las batallas no se deciden entre los hombres que calculan, reflexionan, toman una resolución y la ejecutan, sino entre hombres despojados de esas facultades, transformados, caídos en el nivel de la materia inerte" (Weil, 2005, p. 34).

De modo que todo está regido por la fuerza, "nadie se sustrae a ella en la tierra" (Weil, 2005, p. 40). El mundo humano, de modo análogo al físico, es estructuralmente lucha, generada por relaciones de fuerza que al parecer son necesarias y permanentes; pero que cuando se "ejerce la fuerza", causa opresión, hace de los seres humanos seres frágiles, vulnerables, los expone siempre a la desgracia y a múltiples necesidades (Weil, 2015, p. 46). La fuerza es capaz de cosificar tanto al que la ejerce como al que la sufre; es capaz de sumir en el engańo y en la mentira y sobretodo, es capaz de velar la posibilidad de ver su dinámica.

Ante el impacto de la fuerza, "la carne de los hombres se crispa; el alma humana sin cesar aparece modificada por sus relaciones con la fuerza, arrastrada, cegada por la fuerza de que cree disponer, doblegada por la presión de la fuerza que sufre" (Weil, 2005, p. 15). Ante la desgracia (malheur), causada por el ejercicio de la fuerza, el ser humano se inclina a vivir cubierto por las imaginaciones, por las ilusiones, por bienes y valores aparentes; corre "a las profundidades de la mentira para huir del rostro de la desdicha" (Weil, 1995, p. 85). El orden social, regido por la fuerza, hace vivir en la mentira y la inconsciencia: "No conocemos nuestra miseria. No sabemos que estamos castigados, que estamos en la mentira" (Weil, 2005, p. 96). Teniendo en cuenta esta situación, Simone Weil interpretó el escenario en el que se desarrollaba la existencia humana como una "época tan intoxicada de mentira que convierte en mentira todo lo que toca" (Weil, 1996b, p. 87).

\section{El ser humano sometido a la gravedad}

El ser humano no solo se encuentra sometido a la fuerza y al animal social, sino que también se encuentra entre dos fuerzas que reinan en el universo: por un lado, la gravedad (pesanteur) y por otro, la gracia (grâce); la primera es más visible que la segunda, la cual es prácticamente ignorada. De acuerdo 
con la primera, el ser humano está inserto en el medio material, en un proceso regido por leyes necesarias "análogas a las de la gravedad física"; se encuentra sometido a la necesidad implacable del alma y del cuerpo y a la aspiración del bien, el cual, también es una carencia esencial del ser humano (Weil, 2007b, p. 53).

La gravedad es el movimiento hacia abajo, propio de lo material. De modo análogo al mundo físico, los seres humanos se encuentran sometidos a la fuerza de la gravedad, "siempre hay que esperar que las cosas sucedan conforme a la gravedad" (Weil, 2007b, p. 53). En este sentido, todo cuanto en el ser humano tiende a la bajeza "constituye una manifestación de la gravedad" (Weil, 2007b, p. 53). En el ser humano la gravedad se manifiesta por ejemplo en la tendencia a esperar recompensa cuando se da algo a los demás; a comunicar el sufrimiento; a "extender el dolor más allá de uno mismo, ya sea zahiriendo a otro, ya sea provocando su piedad" (Weil, 2007b, p. 57); a obtener de las personas que se ama (o desear darles) "un consuelo distinto del que nos ofrecen las obras de arte, que nos ayudan por el mero hecho de que existen"; a fabricarnos un dios de nuestro agrado, etc. (Weil, 2007b, p. 107). Los bajos sentimientos, como el deseo de venganza, el odio, el rencor y "todo cuanto es vil y mediocre en nosotros que se rebela contra la pureza del amor y la quiere mancillar" es gravedad; porque, "mancillar es modificar, es tocar; lo bello es lo que no cabe querer cambiar; dominar es manchar; poseer es manchar" (Weil, 2007b, p. 107).

Paradójicamente, "la gravedad moral hace que caigamos hacia lo alto" (Weil, 2007b, p. 55). Es decir, la gravedad inclina al ser humano a pensar que es algo, que tiene un prestigio, que es importante; lo mueve a vivir cubierto por las imaginaciones, por las ilusiones, por bienes y valores aparentes que se atribuyen a las cosas; $\mathrm{y}$ a vivir cubierto con una armadura de mentiras que él mismo crea, la cual lo protege de acontecimientos que sin esa armadura le matarían: "Nuestra vida real está compuesta en más de sus tres cuartas partes de imaginación y ficción; raros son los contactos auténticos con el bien y con el mal" (Weil, 2007b, p. 99). Asimismo, por la fuerza de la gravedad el ser humano vive apegado, alimentado y estimulado por "el dinero, el progreso, la consideración, las recompensas, la celebridad, el poder, los seres queridos"; apegos que pueden llegar a ser "raíces vitales de la existencia carnal" del ser humano y si llegan a faltar pueden herir e incluso 
hacerle morir (Weil, 1996a, p. 134). Al ser humano le es difícil vivir si no es apegado a algo, a un grupo o a un colectivo; esa necesidad es un indicio de su miseria (Weil, 2007b, p. 105). Pues le es cómodo vivir arropado por las mentiras que la sociedad dicta, de ahí que normalmente tenga cuidado de mantener siempre alrededor suyo "las vestiduras de los pensamientos carnales y sociales", porque sabe que si las aparta por un instante moriría de vergüenza (Weil, 1996a, p. 140).

Además, la gravedad se expresa también en el apego a lo superficial; es que "lo bajo y lo superficial están a una misma altura" (Weil, 2007b, p. 54). De este modo, el ser humano vive engañado cuando pone su amor en cosas que no son dignas de él, a pesar de que es consciente de ello. Es evidente, dice Simone Weil, que "todos los bienes de este mundo, pasados, presentes o futuros, reales o imaginarios, son finitos y limitados, radicalmente incapaces de satisfacer el deseo de bien infinito y perfecto que arde perpetuamente en nosotros" (Weil, 1995, p. 33). Sin embargo, el ser humano sigue amando esos bienes finitos, porque sabe que si los deja no podría seguir viviendo. De acuerdo con esto, aceptar la verdad implica la muerte, y elegir la mentira, la vida: "La vida, tal como es, no resulta soportable a los hombres más que por la mentira" (Weil, 1995, p. 16). Ante la luz, el bien, la belleza y la verdad, el alma huye, puesto que:

Todo lo mediocre huye de la luz; y en todas las almas, exceptuadas las que se encuentran próximas a la perfección, hay una gran parte de mediocridad. Esta parte es presa del pánico cada vez que aparece algo de belleza pura, de bien puro; se oculta tras la carne tomándola como un velo (Weil, 1996a, pp. 107-108).

De la misma manera, a causa de la gravedad, al ser humano "le repugna pensar la desgracia", por eso "huye a la mentira con la prontitud con que el animal amenazado de muerte huye al refugio que se abre ante él" (Weil, 2000, p. 30). Esta afirmación pone en evidencia la dificultad de mirar la desdicha de frente y de cerca. Por ejemplo, es duro para el ser humano pensar que un azar o las circunstancias de la vida pueden quitarle todo lo que tiene o pueden abolir lo que es en cualquier momento. Por eso huye de esos pensamientos y se funde en otros. De modo que solo aquel que esté dispuesto a morir a sí mismo, aceptará la desgracia. 
Así pues, la ley que rige el mundo humano es la gravedad, la misma que rige el mundo de los cuerpos físicos: "todos los movimientos naturales del alma se rigen por leyes análogas a las de la gravedad física" (Weil, 2007b, p. 53). Esta situación priva de realidad a la percepción de las cosas porque sofoca la percepción en la imaginación; de modo que solo el "desapego perfecto permite ver las cosas desnudas, fuera de la bruma de valores engañosos" (Weil, 2007b, p. 96). En este sentido, siguiendo las ideas de Platón, Simone Weil invitó a abandonar el engaño de la caverna y la comodidad de la mera opinión; aunque salir de ese mundo imaginario y enfrentar la luz cause sufrimiento y dolor, porque "lo real es duro y rugoso" (Weil, 2007b, p. 97). Por eso es que el ser humano huye de la luz, porque ella le muestra la realidad, los bienes aparentes a los que se encuentra sometido. Si bien, aquí abajo, puede esconderse de la luz "bajo la carne"; en la muerte, ya no podrá hacerlo, entonces quedará desnudo "expuesto a la luz"; eso puede ser, "según los casos, infierno, purgatorio o paraíso” (Weil, 2007b, p. 100).

\section{Lo sobrenatural}

En el orden social, debido al poder de la fuerza, de la colectividad y de la gravedad, "todo está desequilibrado": la relación entre pensamiento y acción, la relación entre cuerpo y espíritu, las relaciones entre seres humanos, las relaciones de los seres humanos con las cosas e incluso con Dios (Weil, 2015, p. 87). No obstante, Simone Weil propone la praxis de la encarnación como la vía para escapar a la dinámica de la fuerza, de la gravedad y del poder de la colectividad.

En 1938 mientras recitaba un poema titulado Love (Amor) de George Herbert (siglo XVII), Simone Weil tuvo la experiencia de la presencia de Cristo. Poco antes de morir, en una carta a su amigo el padre dominico Joseph-Marie Perrin, escribió: "Cristo mismo descendió y me tomó" (Weil, 1996a, p. 41). Sintió en ese momento "una presencia más personal, más cierta, más real" que la de un ser humano, inaccesible tanto a los sentidos como a la imaginación, análoga al amor que se transparentaría a través de la más tierna sonrisa de un ser amado (Weil, 1996a, p. 42). Esta experiencia, al parecer, marcó un punto de inflexión en el pensamiento de Simone 
Weil, pues, como ella misma dice, "desde ese instante el nombre de Dios y el de Cristo se fueron mezclando de forma cada vez más irresistible en mis pensamientos" (Weil, 1995, p. 58). Desde entonces, el sufrimiento de los otros, observado y vivido en carne propia en las horribles condiciones de trabajo en las fábricas, "pasó a ser no solo un problema que exigía una solución sindical y política, sino y sobre todo a ser algo enlazado profundamente con una forma de vida religiosa" (Dolby, 1999, 40). Después de esa experiencia, Simone Weil incorporó en su visión de la realidad, lo sobrenatural, sin que ello haya significado renuncia del mundo material, pues para ella, este era condición del acceso a la realidad sobrenatural.

Según nuestra autora, existe "una realidad situada fuera del mundo, es decir, fuera del espacio y del tiempo, fuera del universo mental del ser humano, fuera de todo el dominio que las facultades humanas puedan alcanzar". Esa realidad es el fundamento, y de ella desciende a este mundo "todo el bien susceptible de existir; toda belleza, toda verdad, toda justicia, toda legitimidad, todo orden, toda subordinación de la conducta humana a las obligaciones"; a esa realidad responde "la exigencia de bien absoluto" que siempre habita "en el centro del corazón del hombre", el cual "no encuentra jamás objeto en este mundo" (Weil, 2000, p. 63).

La sociedad moderna y contemporánea mediante el "dogma del progreso", interpretado por nuestra autora como "el veneno de nuestra época", ha multiplicado las necesidades ilusorias del cuerpo, manteniendo al ser humano sometido a lo que no existe; y ha deshonrado el bien "al convertirlo en una cuestión de modas", ocultando así, los más profundos deseos del alma, y ahogando la sed de espiritualidad (Weil, 1996b, p. 179). Sin embargo, el ser humano percibe que no hay bien verdadero en este mundo, sino bienes aparentes, engañosos y limitados, incapaces de satisfacer el deseo de bien infinito, absoluto y perfecto que arde perpetuamente en el "centro del corazón" (Weil, 2000, p. 63). Pero, parece que el ser humano no quiere mirar de frente esta verdad:

Todos sabemos que no hay bien en este mundo, que todo lo que aquí aparece como bien es finito, limitado, se agota y una vez agotado, la necesidad se muestra al desnudo. Probablemente, en la vida de todo ser humano ha habido algún momento en el que se ha confesado a sí mismo 
con claridad que no hay bien en este mundo. Pero en cuanto se percibe esta verdad se la recubre de mentira (Weil, 1996a, p. 128).

Aceptar esta verdad implica un peligro mortal, pues quien es capaz de hacerlo se desprende con toda el alma de lo transitorio, desvía sus oídos de esas alegrías pequeñas que ofrece la mentalidad actual, "permaneciendo inmóvil, esperando no se sabe el qué, sordo a las solicitaciones y a las amenazas, inconmovible a las sacudidas" (Weil, 1996a, p. 128). Ahora bien, aunque no se sepa con certeza si ese Bien infinito existe, lo que sí se sabe es que "el alma tiene hambre y lo importante es que grite su hambre"; el peligro no es que el alma dude de la existencia de ese Bien, sino "que se deje persuadir de que no tiene hambre" (Weil, 1996a, p. 127). Existe, pues, el hambre no solo de bien, sino también de belleza y verdad absolutas. Y el ser humano percibe que no es posible encontrar en este mundo esos bienes. Esta conciencia del ser humano será la que facilite la apertura hacia lo sobrenatural.

De la misma manera, la búsqueda de la belleza hace posible la apertura hacia lo sobrenatural, pues ella suscita en el ser humano un hambre de bienes de otra naturaleza:

La belleza promete siempre y no da jamás nada; suscita un hambre, pero en ella no hay alimento para la parte del alma que intenta aquí abajo saciarse; solo tiene alimento para la parte del alma que mira. Suscita el deseo, y hace sentir claramente que en ella no hay nada que desear, ya que se quiere ante todo que nada en ella cambie. Si no se buscan recursos para salir del delicioso tormento que inflige, el deseo poco a poco se transforma en amor, y se forma un germen de la facultad de atención gratuita y pura (Weil, 2000, p. 35).

La belleza, la verdad y el bien suscitan un hambre, una necesidad de unión. Simone Weil incitaba a abrazar esa necesidad, porque "el hambre es una relación con el alimento mucho menos completa, ciertamente, pero tan real como el acto de comer" (Weil, 1996a, p. 33). En este sentido, hablando de los sacramentos, afirmaba que, permanecer en el "deseo y la privación" puede constituir "un contacto más puro que la participación en ellos" (Weil, 1996a, p. 33). Ella quería permanecer en el hambre por el miedo a un 
canibalismo que sería una salvaje apropiación. En una carta al padre Perrin expresaba: "Mi situación respecto a usted es semejante a la de un mendigo reducido por la indigencia a un hambre perpetua" (Weil, 1996a, p. 33).

A la realidad sobrenatural pertenece también la gracia sobrenatural, que es "una fuerza que no es de aquí abajo; el contacto con ella no puede compararse a un precio menor que el paso por una especie de muerte" (Weil, 1996b, p. 173). Esta fuerza es sobrenatural y se contrapone desde el exterior a la fuerza de aquí abajo. Esposito (1999) interpreta esta fuerza como aquello que tiene la misma energía que la fuerza de la gravedad, pero con una dirección invertida: "[...] más que de ir de arriba para abajo, como la gravedad, va de abajo arriba, como lo que crece; es fuerza, pero también su opuesto, una fuerza que no es una fuerza, sino, más exactamente, una no-fuerza” (p. 110).

Recordemos que, según nuestra autora, el ser humano se encuentra bajo la opresión de la colectividad, sometido a la fuerza que rige el orden social y a la fuerza de la gravedad. De acuerdo con esto, siempre hay que esperar que las cosas sucedan conforme a la ley de la fuerza y de la gravedad, "salvo que intervenga lo sobrenatural” (Weil, 2007b, p. 53). De esta manera, la gracia sobrenatural se presenta como aquello que puede suspender el mecanismo de la fuerza, pues el ser humano en contacto con la fuerza "no escapa a ella sino por una especie de milagro; esos milagros son raros y de corta duración" (Weil, 2005, p. 35). La gracia sobrenatural puede neutralizar la gravedad, pues, es capaz de elevar lo pesado, de hacer ascender lo grave, sin que deje de ser lo que es. Además, permite escapar al contagio de las influencias sociales: "Solo con la entrada en lo trascendente, en lo sobrenatural, en lo auténticamente espiritual, puede el hombre llegar a ser superior a lo social. Mientras tanto, haga éste lo que haga, de hecho, lo social resulta trascendente en relación al hombre" (Weil, 2007b, p. 193).

De ahí que sea importante que el orden social alimente juntamente al alma y al cuerpo, que dé cabida a lo sobrenatural, que "lo ponga en el centro de la vida del pueblo" (Weil, 2000, p. 85). Porque "solo lo que viene del cielo es susceptible de imprimir realmente una marca sobre la tierra" (Weil, 2000, p. 30). Lo sobrenatural, aunque sea infinitamente pequeño, puede ser "infinitamente activo" (Weil, 2004, p. 47). Su presencia en la 
vida social es transformadora, tiene el poder de penetrar en la injusticia y transformar su lógica. Cuando el ser humano y la sociedad abandonan lo sobrenatural "todo obedece a leyes mecánicas tan ciegas y precisas como la ley de la caída de los cuerpos" (Weil, 1995, p. 68).

\section{La noción de encarnación}

En esta parte se intenta exponer la doctrina weiliana de la encarnación divina, porque, a ejemplo de la divinidad, el ser humano debe realizar el acto de encarnarse, para contravenir al poder de la fuerza, la gravedad y la colectividad.

El pensamiento de Simone Weil acerca de la encarnación divina se articula después de su experiencia mística (1938) y, quizá, se entiende mejor en el contexto teológico de ese momento. Entre 1937 y 1938 se asistía en Francia a los inicios de lo que se ha conocido como la nouvelle théologie, un movimiento de renovación teológica que cuestionaba la naturaleza, el método y la tarea de la teología católica, y se caracterizaba por dos grandes preocupaciones: "el deseo de arraigar la teología en el dato revelado y la inquietud de adaptar el discurso teológico a las cuestiones planteadas por la situación real del hombre" (Vilanova, 1992, p. 869). Uno de los protagonistas de esta nueva teología fue el dominico Marie Dominique Chenu (1895-1990) quien demandaba "una fe cada vez más sensible a las exigencias del misterio de la encarnación", lo cual le conducía a reconocer "no solo la historicidad de la teología, sino también la de las fórmulas dogmáticas y de la misma revelación" (Vilanova, 1992, p. 875). Por ello, ha sido considerado como el "teólogo de los signos de los tiempos" (Gibellini, 1998, p. 218), pues su teología es una "teología optimista de la historia", que "halla su fundamento radical en el realismo de la encarnación, misterio teándrico del Verbo hecho carne, del Espíritu que engendra la historia" (Vilanova, 1992, p. 876).

En este contexto, más allá de un Dios todopoderoso, Simone Weil concibió a Dios como amoroso y misericordioso. Para ella, "la misericordia es un atributo propiamente divino" (Weil, 2003, p. 36). En Intuiciones 
precristianas (octubre 1941-mayo 1942) describió a Dios como un mendigo en búsqueda del amor del ser humano, un Dios que se encarna y viene despojado de su divinidad, escondiendo su divinidad para que el ser humano se acerque:

"Dios busca al hombre con esfuerzo y fatiga y llega hasta él como un mendigo [...]. Dios viene a nosotros completamente despojado, no solo de su poder, sino también de su prestigio. Viene a nosotros escondido, y la salvación consiste en encontrarle" (Weil, 2004, p. 17).

En relación con esta concepción de Dios encontramos la noción weiliana de la encarnación divina, quizá formulada al límite de la ortodoxia católica. Para nuestra autora, la Encarnación significa que: "Dios se hace hombre, se hace materia" (Weil, 2001, p. 375); que "el Amor ha descendido por amor a este mundo, en forma de belleza" (Weil, 2003, p. 17). Se trata de un "un movimiento descendente, que no es gravedad, sino que es amor" (Weil, 2001, p. 649). Con la encarnación "la eternidad desciende para insertarse en el tiempo"; 3 la encarnación "constituye la máxima inserción" (Weil, 2001, p. 413). "La presencia de la belleza en el mundo es la prueba experimental de la posibilidad de la encarnación” (Weil, 2003, p. 27).

Así pues, la encarnación se entiende como descendimiento, abajamiento, como presencia de Dios en el mundo y en el tiempo por amor: "[...] hay como una especie de encarnación de Dios en el mundo, cuya marca es la belleza; lo bello es la prueba empírica de que la encarnación es posible" (Weil, 2007b, p. 183). Pero al mismo tiempo, la encarnación implica un movimiento de retirada, de renuncia y vacío. En este sentido, la Creación, la Encarnación y la Pasión responden a la "locura del amor" de Dios y expresan el "mismo movimiento de retirada" (Weil, 2003, p. 26). Constituyen una locura, porque para realizar el acto de encarnarse y de sufrir la pasión "no existe ni puede existir un motivo o un móvil lógico” (Weil, 2004, p. 127). La Encarnación ha sido el modo que ha tenido Dios para acercarse al ser

3 Ideas similares se encuentran en Charles Péguy (1873-1914) para quien: "La eternidad se ha hecho, se ha convertido en tiempo. Lo espiritual se ha hecho, se ha convertido en temporal" (Citado en Vilanova, 1992, 672). 
humano y al mundo por amor; el cual expresa la autodonación del que ama, a la vez que se retira suscitando la autonomía del ser amado; suscita una unidad absoluta entre los que se aman a la vez que consolida la diferencia entre ellos. Porque "el amor es proporcional a la distancia" (Weil, 1995, p. 29). En este sentido nuestra autora expresa que el amor de Dios:

Mantiene en la existencia, en una existencia libre y autónoma, seres distintos a él, distintos al bien, seres mediocres. Por amor los abandona a la desdicha y al pecado, pues si no los abandonara, no serían. Su presencia les quitaría el ser como la llama quita la vida a una mariposa (Weil, 1995, p. 29).

En virtud de ello, la misma creación ya es una encarnación, puesto que la creación para Dios no consistió en extenderse, sino en retirarse: "Dejó de mandar allí donde tenía ese poder" (Weil, 2003, p. 26). Dicho en otras palabras: "Dios renuncia a ser todo, cede un poco de ser a lo que es distinto de Él” (Weil, 2004, p. 127). Es decir, en lugar de ver la creación como el ejercicio de poder divino, nuestra autora vio que "la creación es abdicación" (Weil, 2003, p. 61). Reemplaza así aquella concepción de creación como ejercicio del poder divino, por la de renuncia de Dios a sí mismo:

La creación no es un acto de autoexpansión por parte de Dios, sino de retirada y de renuncia. [...] Dios ha aceptado esta merma y ha vaciado de sí una parte del ser. [...] Se negó a sí mismo por el acto creador, como Cristo nos ordenó negarnos a nosotros mismos. Dios se negó en nuestro favor para darnos la posibilidad de negarnos por él. Esta respuesta, este eco, que nosotros podemos rechazar, es la única justificación posible a la locura de amor del acto creador (Weil, 1996a, p. 91).

Y la pasión de Cristo es la máxima expresión y el culmen de la renuncia y sacrificio divino: "Dios ha abandonado a Dios; Dios se ha vaciado" (Weil, 2003, p. 61). De esa manera se entiende el grito de Jesucristo en la cruz: Dios mío, ¿̨por qué me has abandonado? (Mt 27, 46).

Según la doctrina cristiana, la encarnación no significa solo estar en un cuerpo al estilo platónico, o parecer un cuerpo; sino que Dios tomó para sí un cuerpo real y verdadero (Atanasio, 2015, pp. 45-46). Realmente se 
hizo un ser humano asumiendo "todas las consecuencias de la encarnación" (Dídimo el Ciego, como es citado en Quasten, 1977, p. 102). Simone Weil coincide también en que "Cristo contó con toda la miseria humana, excepto con el pecado. Pero contó con lo que hace al hombre capaz de pecar. Lo que hace al hombre capaz de pecar es el vacío" (Weil, 2007b, p. 72).

Si la carne de Cristo no es real, nada en su vida, pasión y muerte hubiera sido real. De ahí que muchos autores cristianos desde la antigüedad cristiana se dedicaron a defender la realidad de la encarnación divina. Según Henry (2001) lo que está en cuestión a los ojos de los autores cristianos es la realidad de la encarnación de Cristo y de la carne que ha tomado. Esto es de suma importancia porque:

Si el origen y la naturaleza de Cristo no son idénticos al origen y la naturaleza de nuestra carne en nosotros, entonces encarnándose, no ha tomado realmente nuestra condición, no ha compartido realmente nuestra existencia, no ha padecido realmente el peso de una carne finita como la nuestra, con sus necesidades, por tanto, con su sed, su hambre, su precariedad, con su muerte inscrita en ella desde su nacimiento; si no ha muerto realmente, no ha resucitado tampoco (p. 168).

El Dios que el Nuevo Testamento define como amor (1 Juan 4, 8) no se aferró a la condición divina "[...] sino que se despojó a sí mismo, tomando forma de siervo, hecho semejante a los hombres; y estando en la condición de hombre, se humilló a sí mismo, haciéndose obediente hasta la muerte, y muerte de cruz" (Flp 2, 6-8). Este pasaje es fundamental para Simone Weil, pues para ella la encarnación es renuncia y sacrificio: "Dios se vacía de su divinidad; adopta la forma de un siervo; se somete a la necesidad; se rebaja" (Weil, 1995, p. 29). Este anonadamiento de Dios fue calificado por la filósofa francesa como verdaderamente milagroso:

La prueba, lo verdaderamente milagroso, es para mí la perfecta belleza de los relatos de la Pasión, unida a algunas palabras deslumbrantes de Isaías: «Injuriado, maltratado, no abría la boca» y de san Pablo: «Siendo de condición divina, no se aferró a su categoría de Dios. Se vació... obedeciendo hasta la muerte y muerte de cruz... Fue hecho maldición». Es esto lo que me obliga a creer (Weil, 2011, p. 40). 
La encarnación es pues una kénosis, es decir, un abajamiento de Dios. Este abajamiento hace posible que la divinidad viva bajo las limitaciones de la creatura y padezca las violencias en las que de hecho el ser humano histórico vive. La encarnación implica la decisión de dejar de ser lo que se es, despojarse de sí mismo para asumir la situación y condición de la existencia finita de los seres humanos y compartir el destino con ellos. De este modo, "el impasible padece con el hombre; el soberano se somete a las condiciones históricas en las que rigen la violencia y el sinsentido" (González de Cardedal, 2001, p. 396). Simone Weil entiende la encarnación de la misma manera, como un vaciamiento, como un abajamiento: "Ya antes de la Pasión, ya por la Creación, Dios se vacía de su divinidad, se abaja y toma la forma de esclavo" (Weil, 2003, p. 17). Con estas afirmaciones nuestra autora trata de expresar uno de los conceptos claves de su pensamiento: la encarnación es simultáneamente un acto de generosidad y de negación o renuncia.

Según nuestra autora, no hay manera alguna de formarse una idea de una relación entre Dios y el ser humano sino a través del descenso de Dios. ¿Cómo podría venir él a nosotros sin descender? (Weil, 2007b, p. 133). Este descenso es la encarnación que le hace verdaderamente un ser humano. Pero al mismo tiempo es retirada hasta dejar de ser lo que es, lo cual es contradictorio. Por eso, la encarnación no es del todo inteligible. Israel y Roma desconocieron "la idea de la encarnación", por eso fue posible la Pasión (Weil, 2007b, p. 198). "A Cristo lo mataron de rabia, porque no era Dios" (Weil, 2003, p. 87).

La encarnación de Dios es kenótica porque Dios se presenta dentro del mundo, no como Dios, sino que se muestra bajo los signos de la humildad; lo cual permite no violentar ni coaccionar con su omnipotencia al ser humano. Lévinas ha mostrado también esta condescendencia divina llevándola al extremo de hacerse solidaria del prójimo en su pobreza:

El problema del Hombre-Dios comporta, por una parte, la idea de una humillación que se inflige el Ser supremo, de un descenso del Creador al nivel de la criatura, es decir de una absorción en la pasividad, la más pasiva de la actividad más activa [...] Considero que la humildad de Dios, hasta un cierto punto, permite pensar la relación con la trascendencia en términos distintos de la ingenuidad y del panteísmo; y también que la idea 
de sustitución -bajo cierta modalidad- es indispensable para la comprensión de la subjetividad (Lévinas, 2001, pp. 71-72).

Por último, la encarnación divina es un gesto supremo de amor y de salvación. La encarnación es una kénosis (abajamiento) y esta es a la vez una theósis (elevación, divinización) del ser humano. Porque el Verbo se ha hecho carne "es por lo que podemos entrar en relación con Dios y ser salvados en ese contacto con él” (Henry, 2001, p. 24). En el origen de la encarnación están el amor y libertad infinitos de un Dios que es capaz de una kénosis absoluta, capaz de anonadarse, de tomar la forma de un esclavo, de vaciarse a sí mismo, para llegar al ser humano y atraerlo hacia sí.

Simone Weil reflexiona sobre este punto al pensar en la cruz como balanza, y como palanca. La encarnación, pero sobre todo la Pasión, sería un descenso, como condición de la subida. Dios, "al descender el cielo sobre la tierra, eleva a la tierra hacia el cielo" (Weil, 2007b, p. 131). En este sentido:

La cruz es una balanza en la que un cuerpo endeble y flaco, que sin embargo era Dios, levantó el peso del mundo entero. «Dadme un punto de apoyo, y levantaré el mundo». Ese punto de apoyo es la cruz. No puede haber otro. Hace falta que sea la intersección del mundo con lo que no es el mundo. La cruz es esa intersección (Weil, 2007b, p. 132).

\section{El "acto de encarnarse"}

De acuerdo con lo que se ha visto anteriormente, se puede deducir que Simone Weil concibió la gracia sobrenatural como el auxilio divino para que el ser humano a ejemplo de Jesucristo, pueda realizar la praxis de la encarnación, lo cual favorecerá la encarnación de los bienes trascendentes del bien, la verdad, la belleza, la justicia, etc., en el orden social. A continuación, se expondrán algunos rasgos de la praxis de la encarnación.

Según Simone Weil, el ser humano "no es nada, pero cree que es todo"; el acto de encarnarse consistirá pues en creer que no se es nada; "parecer nada es una imitación de Dios, una acción no activa, como efecto del 
amor $[\ldots]$ al hombre le ha sido dada una divinidad imaginaria para que pueda deshacerse de ella como Cristo de su divinidad real" (Weil, 2001, p. 422). Al respecto, Esposito (1999) comenta que la causa del pecado es la no aceptación de que se es nada; querer ser algo con "la aspiración a serlo todo"; de este modo imitamos de Dios "el atributo de la potencia que el del amor, y el ser, más que el no ser" (pp. 69-70). Ahora bien, según nuestra autora, "nuestro pecado consiste en querer ser, nuestro castigo es creer ser; la expiación es querer no ser; y la salvación consiste para nosotros en ver que no somos" (Weil, 2003, p.149).

En el acto de encarnarse la renuncia es fundamental porque implica el movimiento de retirada: "Dios renuncia -en cierto sentido- a ser todo; nosotros debemos renunciar a ser algo; es el único bien para nosotros"; si Dios se vació de su divinidad, "nosotros hemos de vaciarnos de la falsa divinidad con la que hemos nacido" (Weil, 2007b, p. 82).

En la misma línea, el acto de encarnarse significa la capacidad de vaciamiento, abdicación y retirada como lo hizo Dios en la Creación, Encarnación y Pasión. El concepto que Simone Weil utiliza para explicar este acto de encarnación desde un punto de vista antropológico es el de decreación (décréation), concepto que según Vetö (1994, p. 11) lo habría tomado de Charles Péguy (1873-1914). Este concepto significa "destrucción: hacer que lo creado pase a la nada" (Weil, 2007b, p. 82). No se trata de destruir al hombre en su totalidad, sino esa parte del alma que dice yo:

Nada poseemos en el mundo — porque el azar puede quitárnoslo todo-, salvo el poder de decir yo. Eso es lo que hay que entregar a Dios, o sea, destruir. No hay en absoluto ningún otro acto libre que nos esté permitido, salvo el de la destrucción del yo (Weil, 2007b, p. 75).

Hay pues dos partes en el alma, una "parte mediocre" que rehúye la verdad y odia la luz, porque el contacto con ellas puede significar su destrucción (Weil, 2000, p. 95). Esta parte del alma es la que dice yo, la que "no puede amar la nada, siente horror de ella"; esta es la que hay que destruir (Weil, 2007b, p. 149). La otra parte es "la facultad del amor sobrenatural", que es capaz de "dar su consentimiento" al bien, la verdad, a la luz, a Dios; por ello escapa a la fuerza, mientras que la parte mediocre está sometida a la fuerza (Weil, 2004, p. 49). 
En lo que toca a los hombres e incluso a los dioses de algunas religiones, lo natural es que se ejerza todo el poder del que se dispone: "como el gas, el alma tiende a ocupar la totalidad del espacio que se le asigna"; contener el ejercicio de la fuerza, "va en contra de la naturaleza: solo la gracia lo puede conseguir" (Weil, 2007b, p. 61). Al respecto, Esposito (1999) comenta que para Simone Weil "nuestro mundo no es más que voluntad de poder, hasta que se abra una grieta inesperada y devastadora que nos conduzca fuera del mismo" (p. 107). Así, renunciar a ejercer el poder que se tiene es un acto sobrenatural. Pero, "no debe imaginarse que esto sea fácil, o que el precio a pagar sea bajo: hay que llegar al punto de quebrarse"; implica "partir el alma literalmente en dos: una parte tiende a los resultados de la acción, y la otra no; la primera dice no a recogerse, a desaparecer, a favor del otro, o del Otro; la segunda dice sí" (Esposito, 1999, p. 116). Además de ser difíciles, esos actos de renuncia al ejercicio de poder son muy raros, porque "salvo al precio de un esfuerzo de generosidad, tan raro como el genio se es siempre bárbaro con los débiles" (Weil, 2007a, p. 272). El ser humano "solo escapa a las leyes de este mundo por espacio de una centella; instantes de detenimiento, de contemplación, de intuición pura, de vacío mental, de aceptación del vacío moral; en instantes así es capaz de lo sobrenatural" (Weil, 2007b, p. 62).

El acto de encarnarse consiste también en vaciarse de lo personal, lo cual nos ata al animal social. Lo personal en nosotros es lo relativo al ego, al "prestigio social" y al "derecho a la consideración"; es algo accidental (la apariencia, el prestigio, los talentos, las influencias familiares, etc.), pues "está constante y enteramente expuesto a los azares"; y está ligado a la noción de derecho, con lo cual sumerge al individuo en el juego de fuerzas del animal colectivo (Weil, 1995, p. 76). En este sentido para Simone Weil el ser humano, más que por ser persona, es sagrado en sí mismo, por el solo hecho de ser un ser humano: "En cada hombre hay algo sagrado. Pero no es su persona. [...] Es él, ese hombre, simplemente [...] Ni su persona, ni la persona humana en él, es lo que para mí es sagrado. Es él. Él por entero. Los brazos, los ojos, los pensamientos, todo" (Weil, 2000, p. 17).

Es más, lo que es sagrado, "lejos de ser la persona, es lo que en un ser humano es impersonal” (Weil, 2000, p. 20). Lo sagrado es impersonal, que difícilmente puede ser descrito en el lenguaje social. Lo impersonal es el bien, el amor, la verdad, la belleza, la perfección y la justicia que habitan en 
un "dominio" fuera de este mundo (Weil, 2000, p. 21). Pero "los hombres en colectividad no tienen acceso a lo impersonal" (Weil, 2000, p. 22). De ahí que el orden social debería promover las condiciones para el tránsito de lo personal a lo impersonal. Lo cual: "No se lleva a cabo jamás en quien se piensa a sí mismo como miembro de una colectividad, como parte de un «nosotros» [...] Es preciso que primero se disuelva una colectividad en personas separadas para que la entrada en lo impersonal sea posible" (Weil, 2000, p. 22).

De acuerdo con esto, es preciso que el ser humano escape a lo colectivo, luego se vacíe de su yo para que acceda a lo impersonal (el bien, el amor, la verdad, la belleza, la perfección y la justicia); y para que a través de él esos bienes puedan encarnar en el mundo. Porque, los seres humanos que "han penetrado en el dominio de lo impersonal encuentran allí una responsabilidad respecto a todos los seres humanos" (Weil, 2000, p. 23). Esos bienes encarnan en este mundo únicamente por mediación de quienes de entre los hombres tienen "su atención y su amor" puestos en esos bienes (Weil, 2000, p. 63). No son seres humanos especiales o una especie de seres humanos elegidos, pues cualquiera que ponga su atención y su amor en esa realidad puede hacer descender sobre él el bien, y a través de él irradiar a su alrededor. Ellos están preparados -abriéndose paso por todos los obstáculos que el orden social regido por la fuerza impone- para acceder al bien, a la verdad y a la justicia. Y solo ellos, a pesar de ser pocos y al ser la mayoría ocultos, "operan de manera decisiva por su sola presencia, si están puestos donde es preciso" (Weil, 2000, p. 38).

Es decir, esos bienes trascendentes, aunque estén fuera de este mundo, son capaces de descender y encarnar en este mundo, aunque sea en una medida infinitesimal, y "en determinadas condiciones una acción infinitesimal puede resultar decisiva" (Pétrement, 1997, p. 685). Lo sobrenatural aunque sea "infinitamente pequeño", puede ser "infinitamente activo" (Weil, 2004, p. 47). Por consiguiente, el acto de encarnarse exige al ser humano una conversión, volver su atención y su mirada a la "fuente de la sabiduría" (Weil, 2005, p. 93). Lo cual no es fácil porque implica romper las cadenas que nos atan a la comodidad de la caverna, conlleva a morir a uno mismo. La conversión "es una muerte" (Weil, 2005, p. 94). 
Así pues, el acto de encarnarse, realmente es un acto sobrenatural, porque puede contravenir el mecanismo de la gravedad, de la fuerza y de la máquina social; y quien decida acoger el auxilio de la gracia sobrenatural ya no estará movido únicamente por la fuerza de aquí abajo, sino también por la fuerza que viene de arriba.

En fin, el ser humano, emulando a Dios, "debe hacer el acto de encarnarse", lo cual significa:

Humillarse hasta lo más bajo [...] Salvar el abismo que nos separa de los de grado inferior. Aceptar ser anónimo, ser materia humana [...] Renunciar al prestigio, a la consideración. [...] Despojarse de adornos, soportar la desnudez. [...] Encarnarse. El hombre debe hacer el acto de encarnarse, pues está desencarnado por la imaginación (Weil, 2001, p. 410).

Ese será el modo de llegar a los otros:

En el quicio de la puerta el yo debe despojarse de una parte de sí mismo: de la voluntad, de la imaginación, de toda forma de recompensa o compensación, en definitiva, de todo lo irreal, antes de traspasar el umbral. En este despojamiento del yo consiste la «aceptación del vacío», único camino que conduce al ser, ya que al yo no le queda otra opción que llamar a la puerta y esperar. Es siempre «otro» el que abre la puerta (Weil, 2006, p. 13-14).

En resumen, el acto de encarnarse consiste en: renunciar a la aspiración de ser todo, desistir a ejercer todo el poder que se tiene, destruir el yo egoísta, despojarse de los adornos de lo personal, vaciarse de la imaginación colmadora de vacíos, etc. Ello permitirá al ser humano escapar aunque sea en un grado infinitesimal al animal social, la fuerza y la gravedad; adquirir una actitud consistente en la escucha, la renuncia y la espera; alcanzar la atención del dolor y la desgracia de los otros; amar la verdad y contemplar la belleza del universo; pasar de lo colectivo a lo impersonal y colaborar para que los bienes trascendentes del bien, la verdad, la belleza y la justicia se encarnen en el mundo. 


\section{Conclusión}

Después de este acercamiento al pensamiento de Simone Weil desde la idea de encarnación, podemos concluir que:

Principalmente en la experiencia de la fábrica y de la guerra, Simone Weil descubre que en el orden social vigente, los seres humanos están como náufragos aferrados a una tabla en medio del mar, zarandeados de forma pasiva por la fuerza, la gravedad y la máquina social, abandonados a una colectividad ciega, incapaces, no solo de someter sus acciones a sus pensamientos, sino también de pensar. Pero el peligro más grande no es la tendencia de la fuerza y de lo colectivo a comprimir al individuo, sino la tendencia de la persona a precipitarse y ahogarse en lo colectivo.

En principio, para salir de esa situación, plantea la importancia de que el individuo tome conciencia de la situación en la que vive, de modo que vaya descubriendo poco a poco los mecanismos de la fuerza, de la gravedad y de la máquina social. Aunque también es consciente de la dificultad que ello conlleva, pues según ella: "La vida es mucho más cómoda cuando uno se somete a las peores injusticias y olvida que son injusticias" (Weil, 2005, p. 66). Después, expone que en medio de esa situación en la que se encuentra el ser humano existe otra fuerza que viene de otro mundo; quien decide acogerla, puede, sin salir del orden social, contravenir el mecanismo de la fuerza, la gravedad y la máquina social, aunque sea en un grado infinitesimal. Y lo puede hacer mediante la praxis de la encarnación, es decir, a través de actos concretos de renunciar a la aspiración de ser todo, desistir a ejercer todo el poder que se tiene, destruir el yo egoísta, despojarse de los adornos de lo personal, vaciarse de la imaginación colmadora de vacíos, etc. Esos actos consigen ser tan efectivos que pueden cambiar la vida personal y social. Así, por ejemplo, de acuerdo con la ley de la gravedad, se devuelve lo que se recibe; según la ley de la fuerza la tendencia es ejercer la fuerza de la que se dispone; solo la presencia de un acto sobrenatural a través del amor, puede impedirlo.

Si la Encarnación ha sido el modo que ha tenido Dios de llegar hasta el ser humano y el mundo, de la misma manera, el acto de encarnación es el único modo que tiene el ser humano para llegar a los otros, al Otro, e incluso 
a la naturaleza; y para encarnar en el orden social los bienes trascendentes del bien, la verdad, la belleza y la justicia. Todo ello será posible, con el auxilio de la gracia sobrenatural, puesto que, "las virtudes puramente humanas no germinarían fuera de la naturaleza animal del hombre, sin la luz sobrenatural de la gracia” (Weil, 1990, p. 109).

\section{Referencias}

Atanasio. (2015). La encarnación del Verbo. (José Fernández, Trad.). Madrid: Ciudad Nueva.

Dolby Múgica, María del Carmen. (1999). La filosofía religiosa de Simone Weil. Revista de Filosofía 33, pp. 35-58. Recuperado de: http:// produccioncientificaluz.org/index.php/filosofia/article/view/17983/17972.

Esposito, Roberto. (1999). El origen de la politica. ¿Hannah Arendt o Simone Weil? (Rosa Rius Gatell, Trad.). Barcelona: Paidós.

Gibellini, Rosino. (1998). La Teología del siglo XX. (Rufino Velasco, Trad.). Santander: Editorial Sal Terrae.

González de Cardedal, Olegario. (2001). Cristología. Madrid: BAC.

Henry, Michel. (2001). Encarnación. Una filosofía de la carne. Salamanca: Ediciones Sígueme.

Lévinas, Emmanuel. (2001). Entre nosotros. Ensayos para pensar en otro. (José Luis Pardo, Trad.). Valencia: Pretextos.

Pétrement, Simone. (1997). Vida de Simone Weil. Madrid: Trotta.

Quasten, Johannes. (1977). Patrología (Vol. II). (Ignacio Ońatibia, Ed.). Madrid: BAC.

Vetö, Miklos. (1994). The Religious Metaphysics of Simone Weil. (Joan Dargan, Trans.). Albany, NY: SUNY Press.

Vilanova, Evangelista. (1992). Historia de la teología cristiana (Tomo III). Barcelona: Herder.

Weil, Simone. (1990). Fragmentos de Londres. En Sylvia María Valls (Ed. y Trad.) Simone Weil. Profesión de Fe. Antología Crítica (pp. 97-110). México D. F: Universidad Autónoma Metropolitana. 
Weil, Simone. (1995). Pensamientos desordenados. (María Tabuyo \& Agustín López, Trads.). Madrid: Trotta.

Weil, Simone. (1996a). A la espera de Dios. (María Tabuyo \& Agustín López, Trads.). Madrid: Trotta.

Weil, Simone. (1996b). Echar raices. (Juan Carlos González \& Juan Ramón Capella, Trads.). Madrid: Trotta.

Weil, Simone. (2000). Escritos de Londres y últimas cartas. (Maite Larrauri, Trad.). Madrid: Trotta.

Weil, Simone. (2001). Cuadernos. (Carlos Ortega, Trad.). Madrid: Trotta.

Weil, Simone. (2003). El conocimiento sobrenatural. (María Tabuyo \& Agustín López, Trads.). Madrid: Trotta.

Weil, Simone. (2004). Intuiciones Precristianas. (Carlos Ortega, Trad.). Madrid: Trotta.

Weil, Simone. (2005). La fuente griega. (María Tabuyo \& Agustín López, Trads.). Madrid: Trotta.

Weil, Simone. (2006). Poemas seguidos de Venecia salvada. (Adela Muñoz, Trad.). Madrid: Trotta.

Weil, Simone. (2007a). Escritos históricos y politicos. (María Tabuyo \& Agustín López, Trads.). Madrid: Trotta.

Weil, Simone. (2007b). La gravedad y la gracia. (Carlos Ortega, Trad.). Madrid: Trotta.

Weil, Simone. (2011). Carta a un religioso. (María Tabuyo \& Agustín López, Trads.). Madrid: Trotta.

Weil, Simone. (2014). La condición obrera. (María Tabuyo \& Agustín López, Trads.). Madrid: Trotta.

Weil, Simone. (2015). Reflexiones sobre las causas de la libertady de la opresión social. (Carmen Revilla Guzmán, Trad.). Madrid: Trotta. 